\title{
Effectiveness Of Gravity Concentration For The Beneficiation Of Itakpe (Nigeria) Iron Ore Achieved Through Jigging Operation.
}

\author{
P. A. OLUBAMBI ${ }^{1,2^{*}}$ and J. H. POTGIETER ${ }^{2}$ \\ ${ }^{1}$ Department of Metallurgical and Materials Engineering, \\ Federal University of Technology, Akure, Nigeria \\ ${ }^{2}$ School of Process and Materials Engineering, \\ University of the Witwatersrand, Johannesburg, South Africa
}

\begin{abstract}
:
This study investigates the $e^{1}$ effectiveness of gravity concentration for the beneficiation of Itakpe (Nigeria) iron ore achieved through jigging operations. Iron ore obtained from Itapke Iron Ore Mining Project, Kogi State, Nigeria which contains a very high amount of quartz as revealed by $x$-ray diffraction was crushed using the laboratory dodge crusher and ground in a laboratory ball mill. Particle size analysis was carried out over the range of $+4750 \mu \mathrm{m}$ and $-75 \mu \mathrm{m}$ in 12 different mesh sizes, and the ore was jigged in a Laboratory Denver Mineral Jig. The operating variables used to determine the recovery effectiveness of jigging include; particle size, dilution ratio and bedding thickness. Recovery of iron ore was assessed by determining the percentages of Fe in the underflow and overflow using the Atomic Absorption spectrometry (AAS) method. Optimum iron ore recovery of $71 \%$ was achieved when the jig was operated at medium stroke and speed, with a feed slurry of average dilution and at a particle size of $600 \mu \mathrm{m}$.
\end{abstract}

Keywords: Iron ore; Jigging; Particle size; Dilution ratio; Bedding thickness.

\section{INTRODUCTION}

The Itakpe iron ore deposit has a reserve of about 200 million tonnes with an average iron ore content of 36\%. This has to be beneficiated at a rate of 8 million tonnes per year to produce $64 \%$ Fe concentrate as sinter material for the Ajaoukuta blast furnace and $68 \%$ Fe concentrate as pellet feed for the direct reduction plant at Aladja, all in Nigeria. At this production rate, large quantities of tailings are obtained as waste product of the beneficiated iron ore (Adepoju and Olaleye 2001).

Since the goal of every mineral processing operation/technique is to effectively separate the valuable material from the gangue with minimum metal loss in tailings, the need to develop and employ a sustainable, effective and relatively economical method of separation is imperative. The concentration of the valuable minerals from the gangue involves exploitation of the differences in the mineral properties of the ore after effective comminution (Akande and Olaleye 2000).

\footnotetext{
* Corresponding author; E-mail address: oluwalapatami@yahoo.co.uk, polubambi@yahoo.com (P. A. Olubambi)
} 
Magnetic separation and flotation are the most widely accepted technologies for the upgrading of iron ore particles, but these processes result in iron concentrate with high amounts of very fine and/or interlocked silica particles (Yang, et al 2003). Mohanty (2002) also found that the ability of flotation to treat mixed-phase (middling) and weakly hydrophobic particles is not satisfactory. To address the aforementioned problems and thus to achieve a higher iron ore recovery, several new attempts and technologies are being developed with an added aim of achieving economical and environmental benefits through use of the jigging method (Parkinson, 1989; Yang, 1996; Honaker, et al, 1996; Galvin et al 2002).

The mineralogical characterization of Itakpe iron ore shows that it contains mainly hematite, magnetite and quartz whose specific gravities give sound basis for adopting the gravity concentration technique. In this study, the effectiveness of gravity techniques for concentrating iron ore from bulk Itakpe (Nigeria) iron ore was studied using the jigging method and the effects of operating variables on the recovery of iron ore using the laboratory Denver Mineral Jig were investigated.

\section{MATERIALS AND METHODS}

The bulk ore used in this study was obtained from the Itakpe mine, north of Okene in Kogi State, Middle Belt Region of Nigeria. Its chemical composition as revealed by X-ray fluorescence is as shown in Table1.

TABLE 1: Chemical Composition of Itakpe Iron Ore

\begin{tabular}{|l|l|l|l|l|l|l|l|}
\hline Mineral & $\mathrm{Fe}_{2} \mathrm{O}_{3}$ & $\mathrm{Fe}_{3} \mathrm{O}_{4}$ & $\mathrm{SiO}_{2}$ & $\mathrm{CaO}$ & $\mathrm{Al}_{2} \mathrm{O}_{3}$ & $\mathrm{MgO}$ & $\mathrm{TiO}_{2}$ \\
\hline Composition & 30.88 & 19.05 & 42.05 & 1.25 & 3.20 & 0.37 & 0.20 \\
\hline
\end{tabular}

The ore was broken into sizes that could be fed into the jaw crusher using a sledgehammer. Crushing was carried out in a laboratory dodge crusher and ground in a laboratory ball mill. Ore sieving was carried out using the laboratory sieve shaker as described by Pryor (1965) and Adepoju \& Olaleye (2001) by placing 6000g of the ore in the uppermost ASTM standard sieve. The nest of the ASTM sieves was loaded with the ore and allowed to vibrate for 5 minutes. After the required time, the nest of sieves was taken apart and the amount of material retained on each sieve was weighed. Composition was determined by X-ray fluorescence.

100 grams of the ore of the same size from the product of the sieve analysis was stored in a tray to form the feed or head material for the jigging operation. Steel balls were spread to form a layer on the screen of the mineral jig as a bedding material to varying depths. The spigot of the hutch compartment was plugged with rubber cork and water was added to cover the ragging in the feeding compartment. The head or feed was fed into the feeding compartment. 
Feed material mixed with water at varying dilutions was added to the jig and the jigging process was allowed for 4 minutes. At the end of each jigging operation, the spigot of the hutch compartment was opened and the product was collected as the underflow. The overflow materials left in the feeding compartment were scooped and washed out. The two products (underflow and overflow) were dried, weighed and recorded. The experiments were repeated with varying bedding thickness, dilution rates and particle sizes.

The amount of iron ore in each of the underflow and overflows were evaluated by determining the percentages of Fe in the samples using Atomic Absorption Spectrometry (AAS) method. A sample weight of $2 \mathrm{~g}$ was the standard measurement for this experiment. Samples were dried prior to analysis. Samples were well mixed before weighing to make sure they were homogenous. The samples were digested with $20 \mathrm{ml}$ of 0.01 M Hydrochloric acid (HCL) solution by shaking in plastic centrifuge tubes for 15-20 minutes. Concentration of each of the samples was measured against standard solutions. The composition of iron and silicon in each sample was then ascertained using a Buck Scientific model 200 atomic absorption spectrophotometer with air-acetylene flame.

\section{RESULTS AND DISCUSSION}

The results obtained from the particle size analysis are as shown in Table 2 and the compositional analyses revealed by X-ray are graphically presented in Figures 1, 2 and 3 . Tables 3,4 , and 5 show the results obtained from the jigging operations and they are as graphically illustrated in Figures 4, 5 and 6.

TABLE 2: Particle Size Analysis of Iron Ore

\begin{tabular}{|c|c|c|c|c|c|c|c|}
\hline $\begin{array}{c}\text { Sieve size } \\
\text { Range }(\mathrm{mm})\end{array}$ & $\begin{array}{c}\text { Normal } \\
\text { Aperture } \\
\text { Size } \\
(\mu \mathrm{m}) \mathrm{N}\end{array}$ & $\begin{array}{c}\text { Weight } \\
\text { Retained } \\
(\mathrm{g})\end{array}$ & $\begin{array}{c}\text { Weight } \\
\% \\
\text { retaine } \\
\mathrm{d}(\mathrm{g})\end{array}$ & $\begin{array}{c}\text { Cumula } \\
\text { tive } \\
\text { Wt\% } \\
\text { Retaine } \\
\mathrm{d}(\mathrm{g})\end{array}$ & $\begin{array}{c}\text { Cumula } \\
\text { tive \% } \\
\text { Passing } \\
(\mathrm{g}) \\
\mathrm{P}\end{array}$ & Log N & Log P \\
\hline+4750 & 4750 & 450 & 7.65 & 7.65 & 92.35 & 3.68 & 1.96 \\
\hline$-4750+2000$ & 2000 & 1100 & 19.03 & 26.68 & 73.32 & 3.30 & 1.86 \\
\hline$-2000+1700$ & 1700 & 555 & 9.475 & 36.155 & 63.845 & 3.23 & 1.8 \\
\hline$-1700+1180$ & 1180 & 1160 & 19.85 & 55.985 & 44.015 & 3.07 & 1.64 \\
\hline$-1180+850$ & 850 & 785 & 13.41 & 69.415 & 30.835 & 2.93 & 1.48 \\
\hline$-850+600$ & 600 & 660 & 11.27 & 80.685 & 19.315 & 2.78 & 1.28 \\
\hline$-600+350$ & 350 & 725 & 12.42 & 93.105 & 6.895 & 2.54 & 0.83 \\
\hline$-350+300$ & 300 & 95 & 1.62 & 94.725 & 5.275 & 2.48 & 0.72 \\
\hline$-300+250$ & 250 & 180 & 3.08 & 97.05 & 2.195 & 2.40 & 0.34 \\
\hline$-250+220$ & 220 & 12.5 & .21 & 98.015 & 1.985 & 2.34 & 0.29 \\
\hline$-220+110$ & 110 & 30 & .77 & 98.785 & 1.215 & 2.04 & 0.08 \\
\hline$-110+75$ & 75 & .75 & .015 & 98.80 & 1.20 & 1.87 & 0.07 \\
\hline-75 & -75 & 70 & 1.2 & 100 & 0.00 & 0.0 & 0.0 \\
\hline & & 5848.22 & & & & & \\
\hline
\end{tabular}




\section{Size analysis}

It can be observed from Table 2 that the smaller the aperture of the sieve, the lower the weight\% of Itakpe iron ore retained. The aperture range of $1180 \mu \mathrm{m}$ has the most retained weight\% followed by $850 \mu \mathrm{m}$ and then $2000 \mu \mathrm{m}$ respectively. It was also observed in Table 2 that $2000 \mu \mathrm{m}$ has the most retained quantity of quartz followed by $1180 \mu \mathrm{m}$ then $350 \mu \mathrm{m}$. The rate of reduction of both iron ore and quartz varies (Figures 1 to 3). Quartz dissipates easily, breaking down to fines with little applied stress. Though the hardness value of quartz (i.e. 7 on the Mohr's scale) is a bit higher than the iron ore (Hematite (5.5-6.5), Magnetite (5.5-6), it is far more brittle than iron ore (Gribble, 1988).

The disparity in the cumulative weight\% retained and cumulative passing of the ore is demonstrated by Figures 1 and 2. From both graphs, it can be seen that the cumulative weight\% retained and cumulative passing graphs are inversely proportional to each other. The Gate-Gaudin-Schumann's representation of sieve analysis in Figure 3 shows that the compositional distributions of the materials are linearly and uniformly distributed over a wide size range.

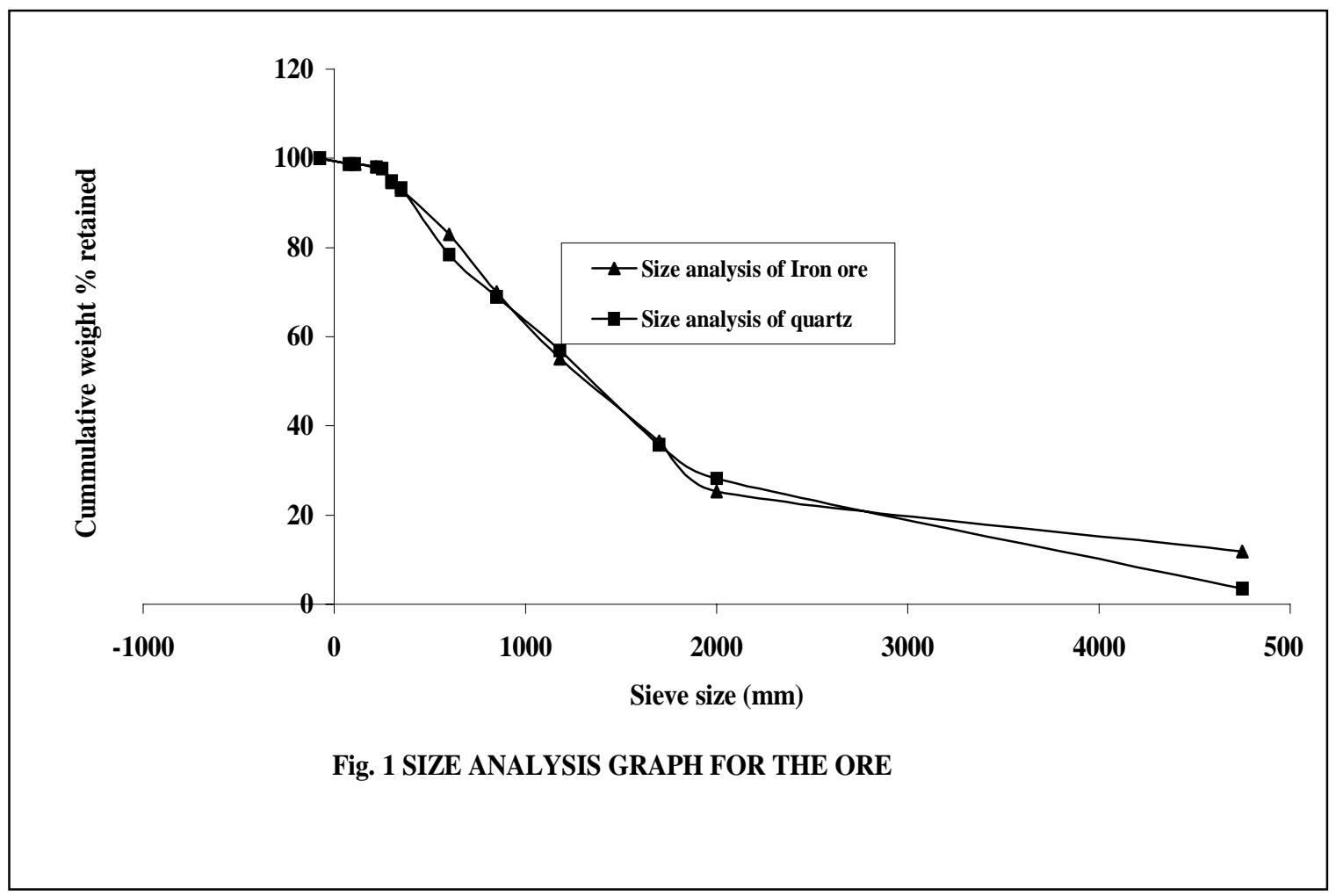

\section{Separation effectiveness:}

The results, as shown in Tables 4, 5, and 6 and Figures 4, 5 and 6, revealed that iron ore concentrate (underflow) was effectively separated from the tailings (overflow), 
which are essentially quartz. Theoretically, effective separation was possible because the quotient of the difference in their specific gravities is greater than 2.5 (Equation 1)
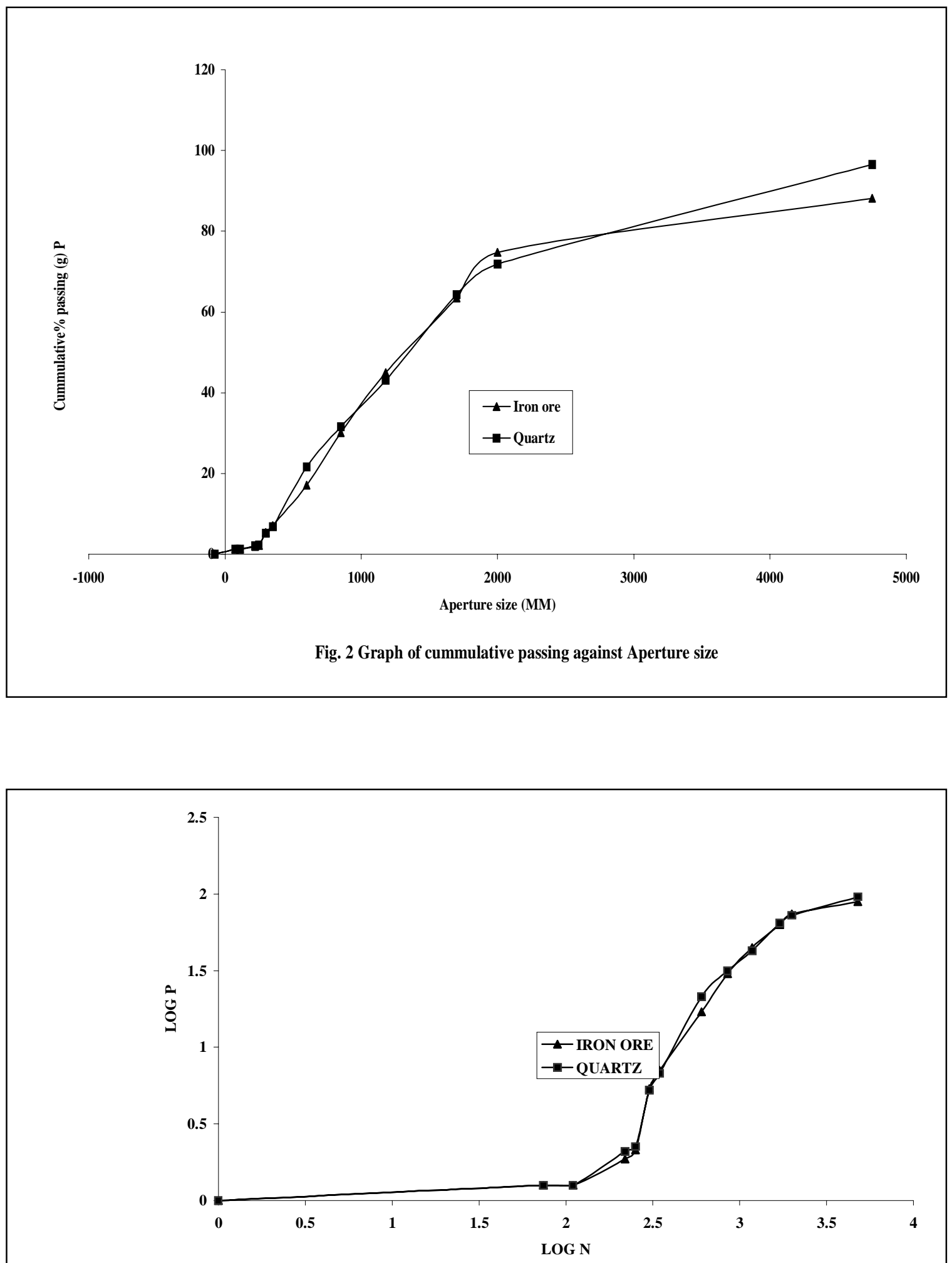

Fig. 3 GATE-GAUDIN-SCHUMAN REPRESENTATION OF SIEVE ANALYSIS 


$$
\frac{D_{h}-D_{f}}{D_{L}-D_{f}}=\frac{6.50-1.0}{2.61-1.0}=3.42
$$

From the same results, it was observed that the overflow, i.e. the tailings still have an appreciable percentage of Fe total. This Fe total in the gangue may come from magnetite in the ore, which was not effectively separated. Recall from the above equation, as the quotient reduces, the effectiveness of the separation reduces. The specific gravity of magnetite is between 4.6 and 5.2, indicating that the quotient varies is between 2.4 and 2.8 .

$$
\frac{5.20-1.0}{2.61-1.0}=2.60 \quad \frac{4.60-1.0}{2.61-1.0}=2.24
$$

Should there be more magnetite of specific gravity 4.6, the efficiency of separation decreases. This will eventually lead to a greater percentage of the $\mathrm{Fe}_{3} \mathrm{O}_{4}$ going to the tailings

\begin{tabular}{|c|c|c|c|c|c|c|c|c|c|c|}
\hline \multirow{2}{*}{$\begin{array}{c}\text { Sieve } \\
\text { Size } \\
(\mu \mathrm{M})\end{array}$} & \multirow{2}{*}{$\begin{array}{c}\text { Feed } \\
\text { (g) }\end{array}$} & \multicolumn{4}{|c|}{ UNDERFLOW } & \multicolumn{4}{|c|}{ OVERFLOW } & \multirow{2}{*}{$\begin{array}{c}\% \\
\text { Losses } \\
100- \\
\left(x^{+} y\right)\end{array}$} \\
\hline & & $\begin{array}{l}\text { Wt } \\
\text { (g) } x\end{array}$ & $\% \mathrm{Fe}$ & $\% \mathrm{Si}$ & $\begin{array}{c}\text { Ratio } \\
\text { of } \\
\text { Conc } \\
\text { entrat } \\
\text { ion }\end{array}$ & $\begin{array}{l}\text { Wt } \\
\text { (g) y }\end{array}$ & $\% \mathrm{Fe}$ & $\% \mathrm{Si}$ & $\begin{array}{c}\text { Ratio } \\
\text { of } \\
\text { Conc } \\
\text { entrat } \\
\text { ion }\end{array}$ & \\
\hline 1180 & 200 & 40 & 65.4 & 34.6 & 1.89 & 150 & 30.4 & 69.6 & 2.29 & 10 \\
\hline 850 & 200 & 110 & 67 & 33 & 2.03 & 90 & 31.5 & 68.5 & 2.17 & 0 \\
\hline 600 & 200 & 130 & 70.5 & 29.5 & 2.39 & 70 & 33.4 & 66.6 & 1.99 & 0 \\
\hline
\end{tabular}

TABLE 3: Jigging Operation with Thin Bed, Average Dilution with Medium Stroke and Speed

\begin{tabular}{|c|c|c|c|c|c|c|c|c|c|c|}
\hline \multirow{2}{*}{$\begin{array}{c}\text { Sieve } \\
\text { Size } \\
(\mu \mathrm{M})\end{array}$} & \multirow{2}{*}{$\begin{array}{c}\text { Feed } \\
\text { (g) }\end{array}$} & \multicolumn{4}{|c|}{ UNDERFLOW } & \multicolumn{4}{|c|}{ OVERFLOW } & \multirow{2}{*}{$\begin{array}{c}\% \\
\text { Losses } \\
100- \\
(x+y)\end{array}$} \\
\hline & & $\begin{array}{l}\text { Wt } \\
\text { (g) } \mathrm{x}\end{array}$ & $\% \mathrm{Fe}$ & $\% \mathrm{Si}$ & $\begin{array}{c}\text { Ratio } \\
\text { of } \\
\text { Conc } \\
\text { entrat } \\
\text { ion }\end{array}$ & $\begin{array}{c}\mathrm{Wt} \\
\text { (g) } \mathrm{y}\end{array}$ & $\% \mathrm{Fe}$ & $\% \mathrm{Si}$ & $\begin{array}{c}\text { Ratio } \\
\text { of } \\
\text { Conc } \\
\text { entrat } \\
\text { ion }\end{array}$ & \\
\hline 1180 & 200 & 55 & 61.5 & 38.5 & 1.59 & 125 & 26.5 & 72.5 & 2.77 & 20 \\
\hline 850 & 200 & 110 & 61 & 39 & 1.56 & 80 & 68.5 & 31.5 & 2.17 & 10 \\
\hline 600 & 200 & 110 & 60.5 & 39.5 & 1.53 & 90 & 67.5 & 32.5 & 2.08 & 0 \\
\hline
\end{tabular}

TABLE 4: Jigging Operation with Thin Bed, Excess Dilution with Medium Stroke and Speed 
TABLE 5: Jigging Operation with Thick Bed, Excess Dilution with Medium Stroke and Speed

\begin{tabular}{|c|c|c|c|c|c|c|c|c|c|c|}
\hline \multirow{2}{*}{$\begin{array}{c}\text { Sieve } \\
\text { Size } \\
\text { (NM) }\end{array}$} & \multirow{2}{*}{$\begin{array}{c}\text { Feed } \\
\text { (g) }\end{array}$} & \multicolumn{4}{|c|}{ UNDERFLOW } & \multicolumn{4}{|c|}{ OVERFLOW } & \multirow{2}{*}{$\begin{array}{c}\% \\
\text { Losses } \\
100- \\
(\mathrm{x}+\mathrm{y})\end{array}$} \\
\hline & & $\begin{array}{c}\mathrm{Wt} \\
\text { (g) } \mathrm{x}\end{array}$ & $\% \mathrm{Fe}$ & $\% \mathrm{Si}$ & $\begin{array}{l}\text { Ratio } \\
\text { of } \\
\text { Conc } \\
\text { entrat } \\
\text { ion }\end{array}$ & $\begin{array}{l}\mathrm{Wt} \\
\text { (g) } \mathrm{y}\end{array}$ & $\% \mathrm{Fe}$ & $\% \mathrm{Si}$ & $\begin{array}{l}\text { Ratio } \\
\text { of } \\
\text { Conc } \\
\text { entrat } \\
\text { ion }\end{array}$ & \\
\hline 1180 & 200 & 110 & 66.5 & 33.5 & 1.98 & 90 & 31. & 68.3 & 2.15 & 0 \\
\hline 850 & 200 & 120 & 67 & 33 & 2.03 & 70 & 30.5 & 69.5 & 2.28 & 10 \\
\hline 600 & 200 & 110 & 66.8 & 33.2 & 2.01 & 85 & 28 & 72 & 2.57 & 5 \\
\hline
\end{tabular}

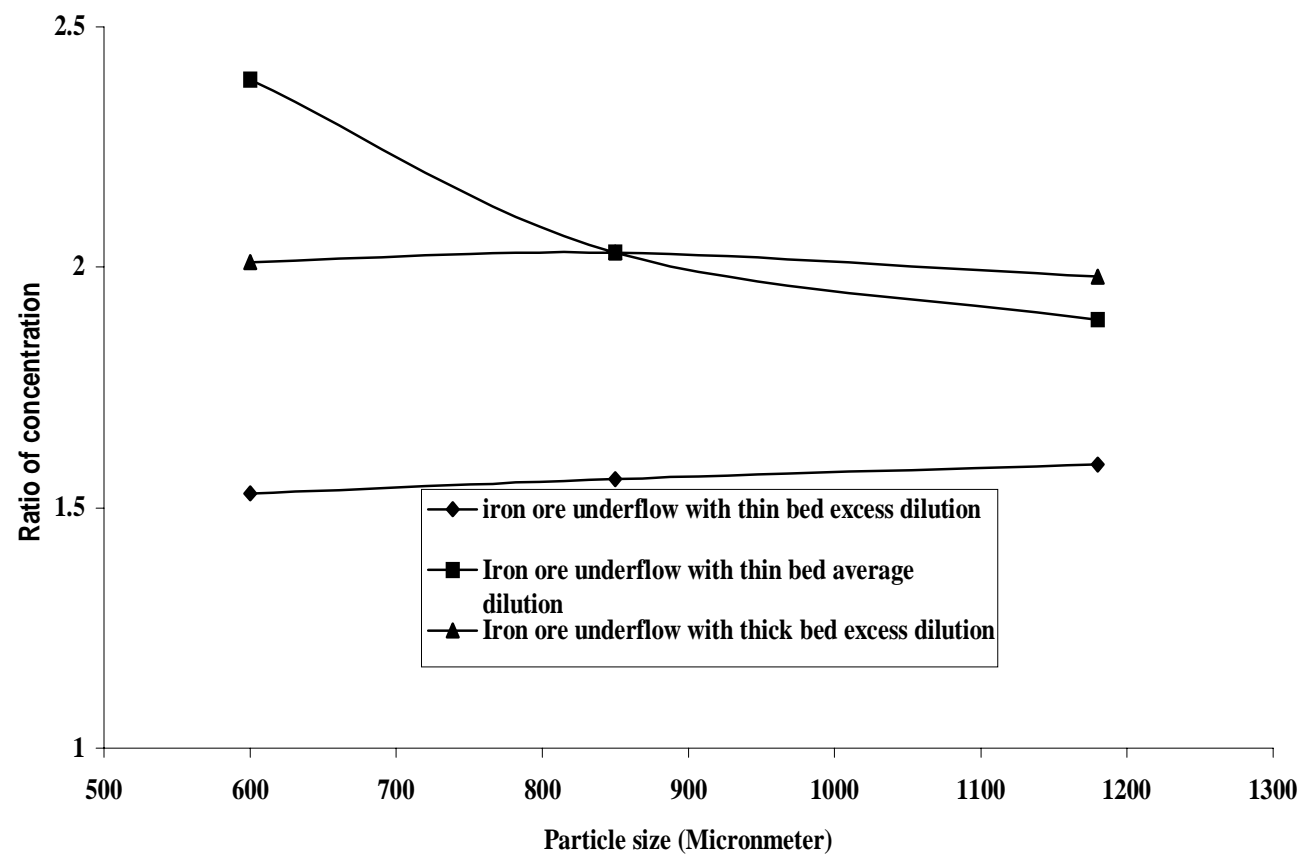

FIG. 4 Graph of Ratio of concentrate against particle size

\section{Effects of dilution ratio:}

The influence of dilution on the recovery of iron ore using jigging is as revealed in Tables 4, 5, and 6. The volume of water in the hutch compartment of the laboratory mineral jig provides the necessary dilation required for particles separation. The highest recovery was achieved with average dilution. Low dilution (higher percent solids) led to hindered settling, with a decrease in the falling rate of particles leading to overcrowding in the fixed hutch compartment. Excess dilution gave rise to randomness of particles in the same fixed hutch compartment. With medium dilution, a state of free settling sets in where the possibility of particle crowding was very negligible. 


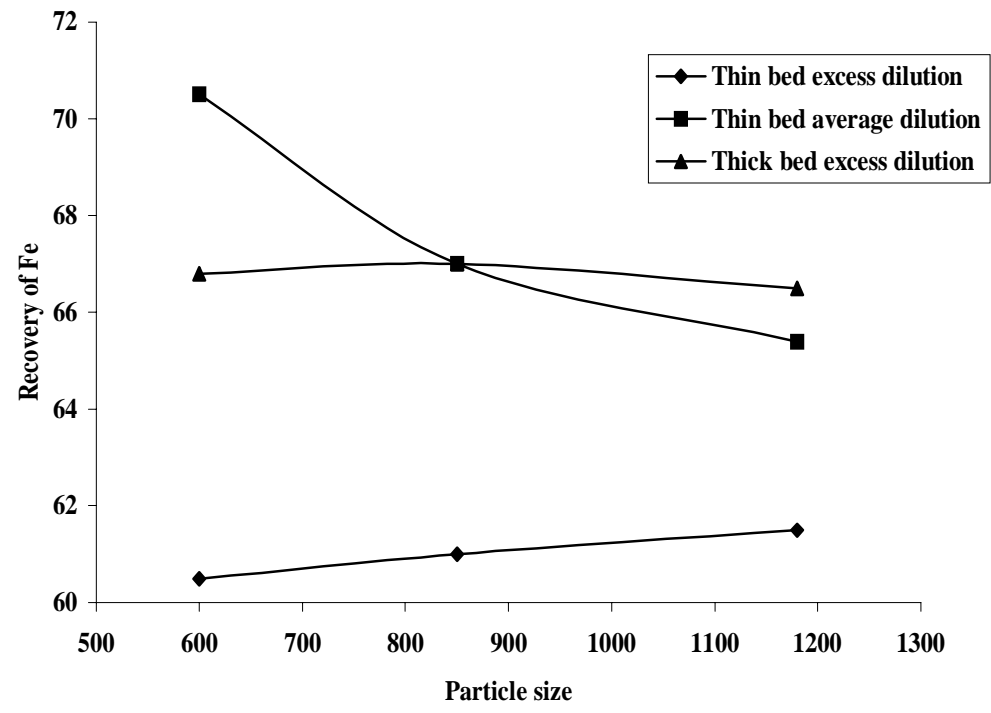

FIG. 5 Graph of rate of recovery of Fe against particle size.

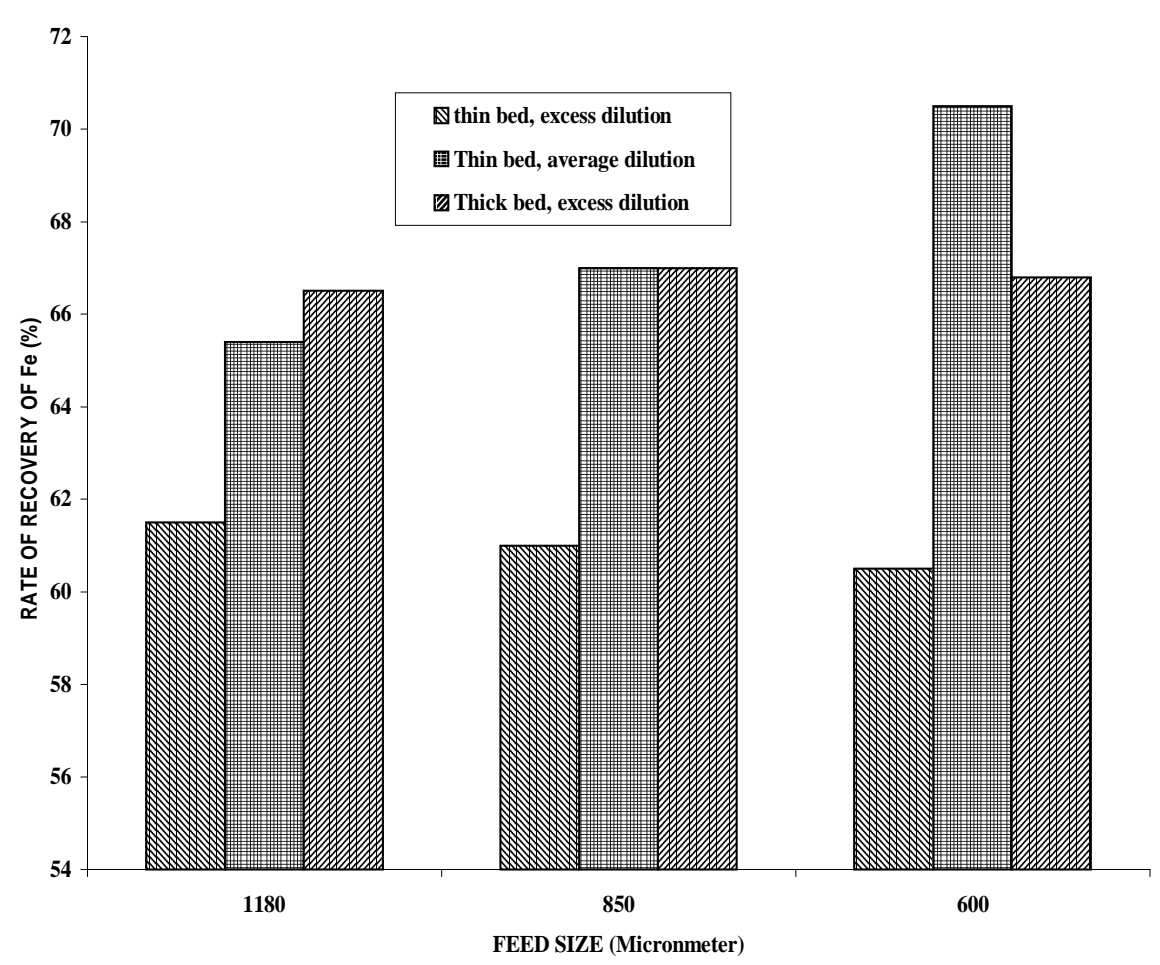

Fig. 6 FFECT OF FEED SIZE ON RATE OF RECOVERY OF Fe 


\section{Effects of bedding thickness}

The effects of bedding material and thickness of the bed on the recovery of iron ore are shown in Figures 4, 5 and 6. The bedding material and the thickness of the bedding materials used has an effect on the \%Fe recovered as shown in Figure 6. Thick bedding causes more friction action during the suction stage, making concentration less possible. Thin bedding reduces friction during suction and also, allows easy passage of the Fe concentrate during jigging.

\section{Effects of Particle size:}

The effect of the particle size on the recovery of iron ore is also shown in Tables 4,5, and 6, and Figures 4, 5 and 6. The highest recovery was achieved at 600 $\mu \mathrm{m}$. Lower separation efficiency in finer particles is believed to be caused by the negligible mass associated with this size particles. Particles so small, that settle in accordance with Stroke's law, are unsuitable for concentration (Wills, 1989). Lower recovery of Fe at larger particle sizes may be due to the reduced possibilities of the larger particles passing through the jig screen. A coarser particle will have a reduced chance of passing through the jig screen and thereby will report to the overflow as tailings (Mohanty, et al 2002).

\section{CONCLUSION}

The results of this project work have clearly shown that effective separation of iron ore concentrate from bulk Itakpe iron ore by jigging operations is possible. It is clearly revealed that the effectiveness of the separation was greatly influenced by the operating variables of the jig and the particle size of the ore. The result of the work has also shown that the optimum Fe recovery could be achieved when the jig is operated at medium stroke and speed under the conditions of a thin bed with feed slurry of average dilution at a particle size range of $600 \mu \mathrm{m}$.

\section{REFERENCES}

Adepoju, S. O. and Olaleye, B. M., (2001). Gravity concentration of silica sand from Itakpe iron-ore tailings by tabling operation. Nigerian Journal of Engineering Management. Vol. 2, No. 2, 51-55.

Akande, J. M. and Olaleye, B. M., (2000). Recovery of Galena concentrate from leadZinc ore by jigging operation. Proceedings of the $18^{\text {th }}$ Annual Conference of the Institute of Science and Technology. $28^{\text {th }}$ Nov. $-1^{\text {st }}$ Dec. 2000.

Galvin, K.P., Pratten, S.J., Lambert, N., Callen, A.M., and Lui, J. (2002). Influence of a jigging action on the gravity separation achieved in a teetered bed separator. Minerals Engineering 15, 1199-1202.

Gribble, C.D; (1988), Rutley's element of mineralogy, $27^{\text {th }}$ edition, London Pg. 235-6 and 427-9. 
Honaker, R.Q., Wang, D., Ho, K., (1996). Application of the Falcon concentrator for fine coal cleaning. Miner. Eng. 9 (11), 1143-1156.

Mohanty, M. K., Honaker, R. Q., and Patwardhan, A. (2002). Altair jig: an in-plant evaluation for fine coal cleaning. Minerals Engineering 15, 157-166

Parkinson, J.W., (1989). Centrifugal jig coal cleaning feasibility test results, Interim Report prepared for Electric Power Research Institute (EPRI), California and Empire State Electric Energy Research Corporation, NY.

Pryor, E.J. (1965), Mineral processing, Elsevier Publishing Co. Ltd. Amsterdam London - New York

Wills B.A; (1989), Mineral Processing Technology, An introduction to the Practical aspect of ore treatment and mineral recovery. $3^{\text {rd }}$ edition, Pergamon, New York.

Yang, D. C., Bozzato, P., and Ferrara, G. (2003). Iron Ore Beneficiation with Packed Column Jig. Journal of Minerals \& Materials Characterization \& Engineering, Vol. 2, No.1, pp43-51, 2003. 